\title{
CRM Software for Small and Medium Agro enterprises
}

\author{
V V Sumanth Kumar, Praneetha Y and Damini Thakur \\ Senior Scientist, Young Professional and PGDMA Scholar at ICAR-National Academy for \\ Agricultural Research Management, Rajendranagar, Hyderabad.
}

\section{E Mail: sumanth.naarm@gmail.com \\ Mobile: 9502932222}

\begin{abstract}
:
The key enabler for long-term sustenance of any organization, greatly depends on its ability to maintain strong and continuous relationship with its customers. In support to that, any technology enhanced, all-inclusive electronic Customer Relation Management (e-CRM) software, would directly complement the organization's performance by offering help in terms of identifying the potential customers and further plan various smart strategies to retain them. This article describes one such application built by using a free and open source Sugar CRM software developed at ICAR-NAARM to assist Small and Medium Agro-enterprises for automating their sales, marketing and customer service functions.
\end{abstract}

Keywords: CRM software, Agro enterprises, Sales Automation, Service Mangement.

\section{Article:}

Agro-enterprises with their core set of Production, Processing, Marketing, Distribution and other diverse activities, often happen to come across a huge customer base and managing and retention of those customers is the major determinant of success. Customer satisfaction has high implication on the economic performance of a firm and it is a well-established fact that, loyalty and long-term engagement of the customers, especially with the small and medium enterprises, is greatly impacted by the frequency of communication the enterprise makes with them. In light of this, Customer Relation Management supplemented by software solutions is a great addition to the organization's functionality as that comes with built-in features like marketing automation for sales enhancement, cloud powered customer database storage, Customizable dashboard settings to suit to the diverse needs of different customer groups specific to an enterprise and many more.

SUGARCRM is one such open source, customizable free software solution which offers highly automated knowledge-driven support tools that could hence reach and been serving 2 million people globally. This solution as for the agriculture industry concerned like any other, enables any collaborating enterprise to reach and effectively manage the relationships with the 
potential customers, taking over the most tedious, conventional and relatively less effective means of physically reaching the customers through Sales representatives. This software ensures, the enterprises serve the customers in a better way on day-to-day basis through automation of sales, marketing and customer relation services. Application of this customer centric CRM software in any especially small or medium agro-enterprise serves as an integrated approach as it has data warehousing technology that helps to present aggregate customer information from across multiple channels from various departments and after analyzing the information, it is even possible to provide On-premise one-to-one customized service through customer segmentation which is also an automated feature of the CRM software.

An application is developed for a PGDMA student at ICAR-NAARM (https://pgdma.in/damini/) using a free, open source SUGARCRM software to assist the marketing management of small and medium agro-enterprises they are dealing with. This application helps in basic understanding of the firms' customer relations through analytics presented by the software. We have used the cloud storage implied configuration to maintain the entire database furnishing the details of large number of customers and greater volumes of their transactions. This application helps any enterprise with password protected, admin friendly dashboard which is totally specific and customizable to serve different groups of customers, be that suppliers, purchasers, wholesale dealers, farmers etc., as in the case with agro-enterprises.

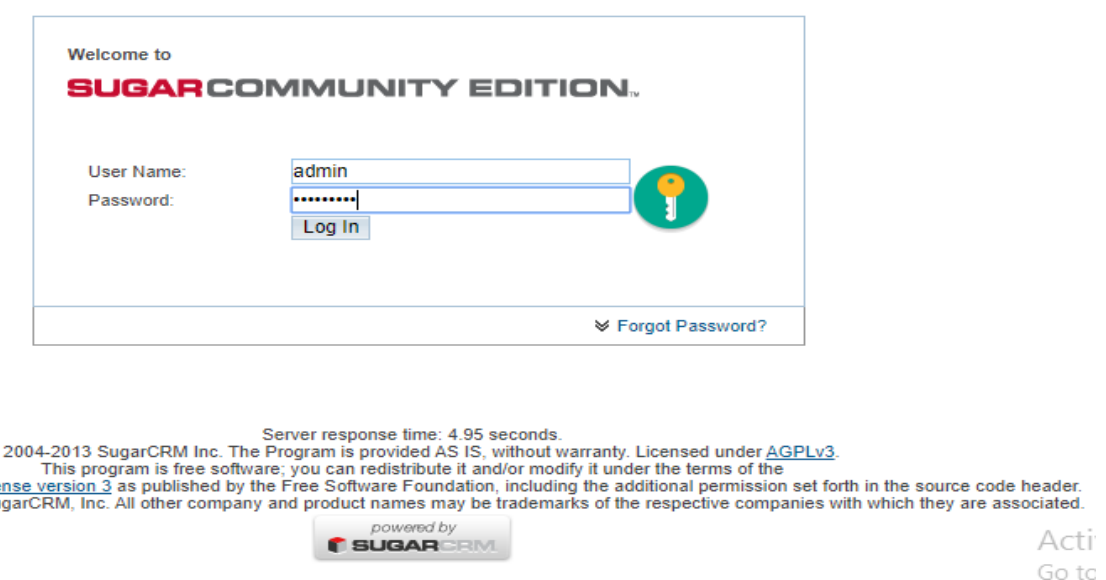

The Admin dashboard displays the comprehensive outlook of logs of the entire business activities right from details of sales and marketing transactions made by the customers along with the record of various activities and correspondences through calls, meetings scheduled or emails, made by the enterprise in that regard of customer service. Also, the software based on the details stored in the customer database, present the analytics in terms of top opportunities or target customers based on which the enterprise should impose 
focus, in reaching them on priority basis and also can identify to working on the weaker areas as well.It is made possible that any number of employees within the enterprise can be registered and access the common dashboard with one's specific username and password.

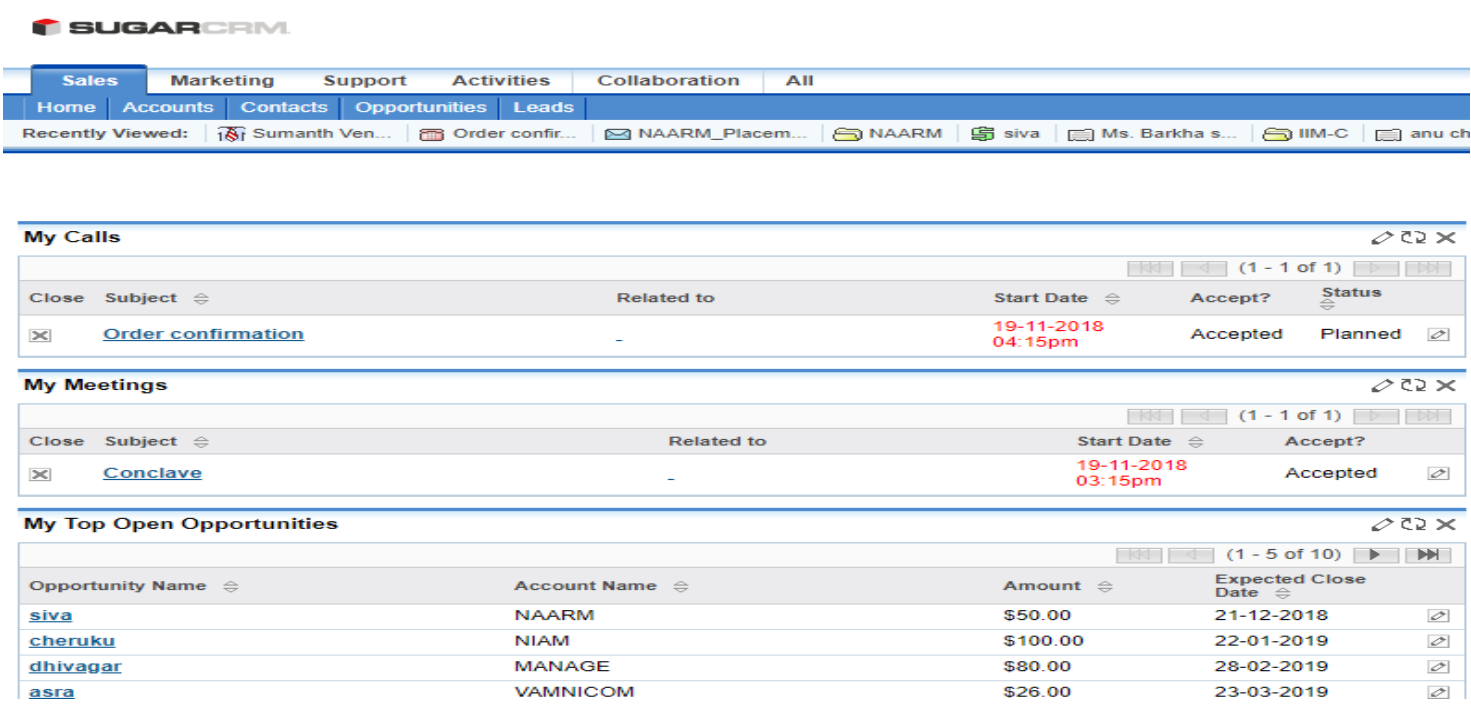

This software integration serves as a "smart approach strategy" by the enterprises in efficient and timely serving of the customers, as supported by the automated tools of customer segmentation and even in sending personalized emails using a single template and common text to a large group of customers who can be reached in a similar way, all at once. Also, it is possible to attach files of any format along with the emails sent.

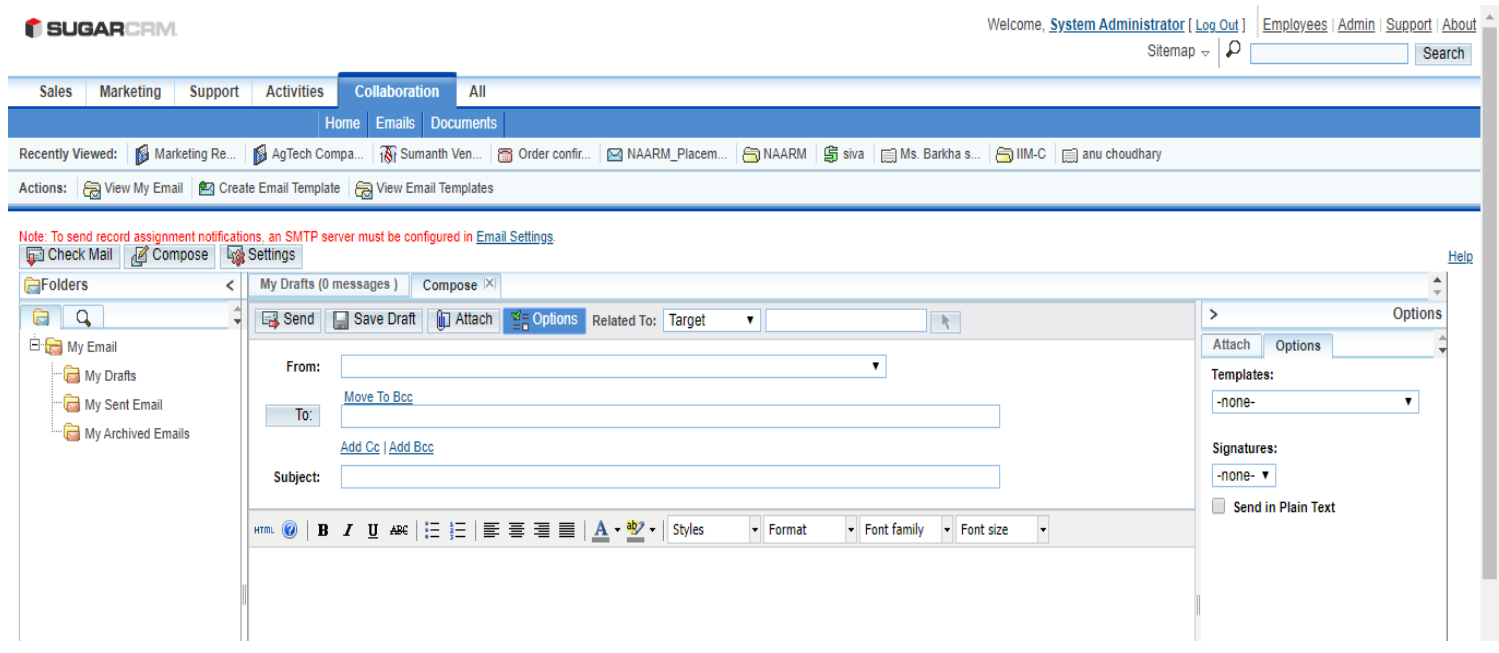


The software also facilitates for easy identification of specific leads and customers from among a large group, through display of complete assembled information required to reach them, thus renders time effectiveness greatly. It thus makes possible for the enterprise in leveraging the marketing automation platform for effective lead nurturing through planning and organizing strategic campaigns. Thus, on the whole, this software integration ensures Sales and Marketing operations are in perfect alignment.

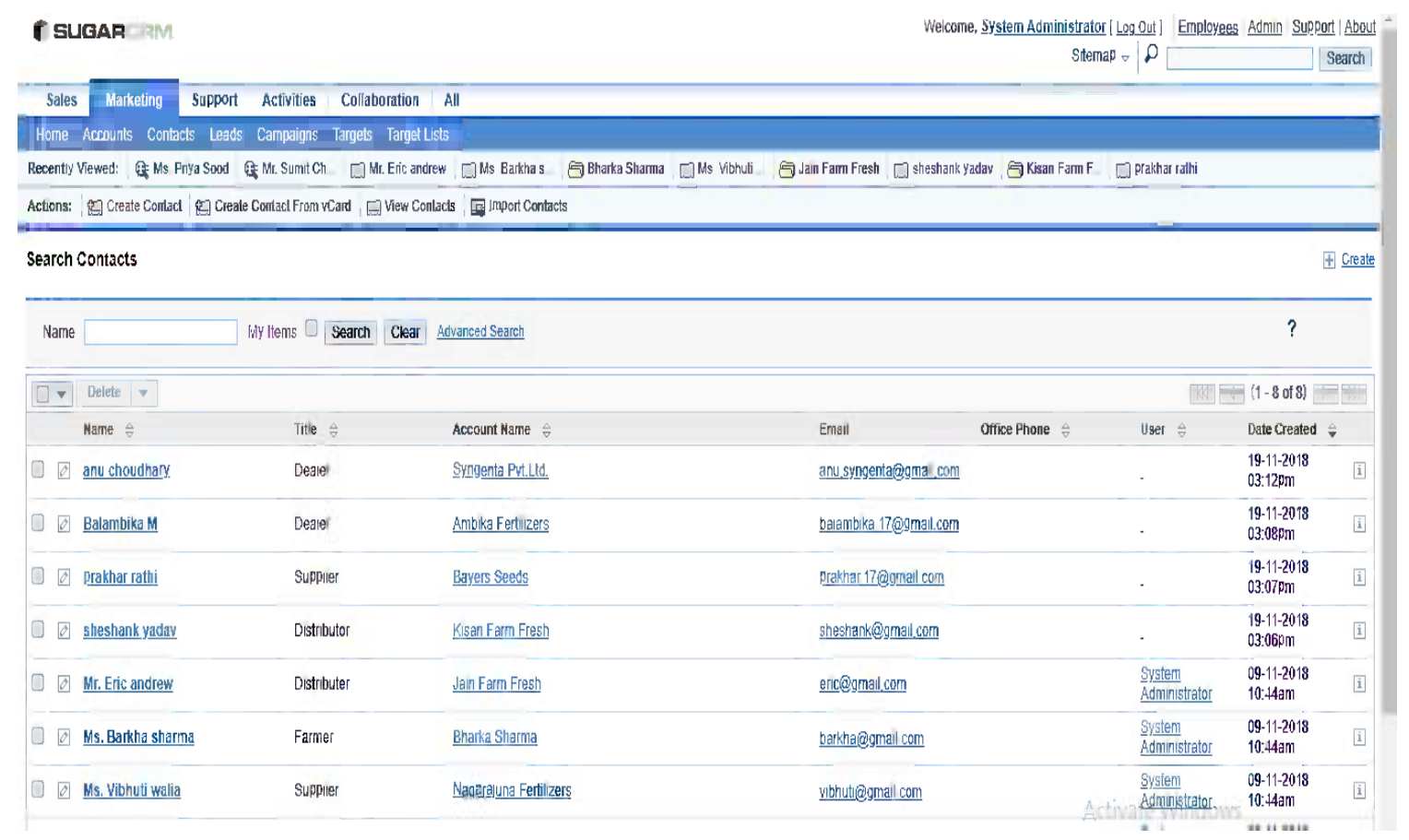

Therefore, when it is well established that stronger customer relationships greatly add to the growing market share of any agro-enterprise, leveraging digital technology in that regard through integration of all-inclusive automated CRM software amplifies eases the process and renders competitive advantage over the other firms.

\section{References:}

1. About SUGARCRM software https://www.sugarcrm.com/

2. Molivic B., (2012). Application of Customer Relation Management (CRM) in Agriculture. Polish Journal of Management Studies. Vol 6. http://oaji.net/articles/2014/1384-1415186132.pdf

3. Enmain, (2019). Use of CRM Strategy in Agriculture Industry. https://www.enmain.com/customer-relationship-management/use-of-crm-strategy-inagriculture-industry/

4. Aylin Barnes (2012). Change Management in Agriculture Industry. https://www.crmsystems.com/Blog/Postld/187/change-management-in-agriculture . 